\title{
An index from sap flow records to schedule irrigation in super-high density olive orchards
}

\author{
J.E. Fernández, S. Elsayed-Farag and M.V. Cuevas \\ Instituto de Recursos Naturales y Agrobiología \\ de Sevilla (IRNAS, CSIC) \\ Avenida Reina Mercedes 10, 41012-Sevilla, Spain.
}

\author{
M.J. Martín-Palomo \\ ETSIA, Departamento de Ciencias \\ Agroforestales. Ctra. de Utrera \\ km 1, 41013-Sevilla, Spain.
}

Keywords: Olea europaea, water relations, stem water potential, crop management

\begin{abstract}
Regulated deficit irrigation (RDI), recommended for super-high density (SHD) olive orchards, requires a precise control of irrigation. Water must be supplied on the phenological stages when the plant is most sensitive to water stress, but irrigation promotes plant vigour, and excessive growth hampers management in SHD orchards. A reliable water stress indicator is needed, therefore, for the proper management of RDI. Here we present an evaluation of the performance of $D_{E \mathrm{p}}$, an index previously reported by Cuevas et al. (2012). The index is derived from sap flow measurements in RDI trees and in fully irrigated trees used as a reference. We evaluated the index during the irrigation seasons of 2011 and 2012, in an 'Arbequina' olive orchard with 1667 trees ha ${ }^{-1}$ close to Seville, southwest Spain. The index showed a potential for scheduling RDI strategies, although its reliability decreased on periods of fluctuating atmospheric demand. The required data analyses and data interpretation make the $D_{E p}$ index suitable for well-trained users only.
\end{abstract}

\section{INTRODUCTION}

Irrigation management in hedgerow olive orchards with plant densities above ca. 1500 trees per hectare, also called super-high density (SHD) olive orchards, is a challenge. Badly managed irrigation may led to excessive growth. This causes low radiation interception by the lower part of the canopy, it hampers mechanical harvesting and, in the end, it might shorten the productive life of the orchard (Connor 2006, León et al, 2007). Both sustained deficit irrigation (SDI) and regulated deficit irrigation (RDI) are used in SHD olive orchards (Grattan et al., 2006; Gómez-del-Campo, 2011). With RDI irrigation amounts (IA) can be adjusted to changes in the sensitivity of the olive tree to water stress depending on the phenological stage. This requires a reliable indicator of water stress. Recently Cuevas et al. (2012) used sap flow measurements to derive an indicator which they reported to have a potential for being used in SHD olive orchards under RDI. Still, they pointed out some limitations of the indicator, so the aim of this work was to extend its evaluation for two additional irrigation seasons to gather additional information on its potential and limitations.

\section{MATERIALS AND METHODS}

The experiments were made in 2011 and 2012, in a commercial SHD olive orchard near Seville, southwest Spain. The trees, cv. Arbequina planted at $4 \mathrm{~m} \times 1.5 \mathrm{~m}$, ca. $2.10 \mathrm{~m}$ wide and ca. $2.5 \mathrm{~m}$ high, were 5-year-old in 2011. The orchard had a sandy loam top layer of ca. $0.6 \mathrm{~m}$ depth and a clay layer, not explored by the roots, downwards 
(Cuevas et al., 2012). Average values in the area of potential evapotranspiration $\left(\mathrm{ET}_{\mathrm{o}}\right)$ and precipitation $(P)$ are $1541.5 \mathrm{~mm}$ and $534.0 \mathrm{~mm}$, respectively (2002-2012 period).

We had three irrigation treatments in a randomized block design with four $12 \mathrm{~m} \times$ $16 \mathrm{~m}$ plots per treatment. Each plot contained 8 central trees surrounded by 24 border trees. All measurements were made in central trees. We had a full irrigation (FI) treatment, in which the trees were daily irrigated to replace irrigation needs (IN) all along the irrigation season, and two RDI treatments scaled to a total irrigation amount (IA) of $60 \%$ (60RDI) and 30\% IN (30RDI). The RDI strategy is described in Fig. 1, and details on the irrigation supplies are given in Figs. 2a,b. In all plots the irrigation system consisted of one drip line per tree row with a $2 \mathrm{~L} \mathrm{~h}^{-1}$ dripper every $0.5 \mathrm{~m}$. The IN values were calculated as $\mathrm{IN}=\mathrm{ET}_{\mathrm{c}}-P_{\mathrm{e}}$, being $\mathrm{ET}_{\mathrm{c}}$ the maximum potential crop evapotranspiration calculated with the crop coefficient approach (see Fernández et al., 2011 for details) and $P_{\mathrm{e}}$ the effective precipitation calculated as $75 \%$ of the precipitation recorded in the orchard. All trees were fertigated to cover the nutritional needs (Cuevas et al., 2012).

We used a Profile probe (Delta-T Devices Ltd, Cambridge, UK) and two access tubes per plot, at ca. $0.5 \mathrm{~m}$ from the tree trunk, to estimate the volumetric soil water content $\left(\theta_{\mathrm{v}}\right)$ in every plot. In each access tube we measured $\theta_{\mathrm{v}}$ at $0.1,0.2,0.3,0.4,0.6$ and $1.0 \mathrm{~m}$ depths, 1-2 times per week, all along the irrigation seasons. The Profile probe was calibrated in situ by Fernández et al. (2011). From the estimated $\theta_{\mathrm{v}}$ values we calculated the relative extractable water (REW) in the root zone as REW $=\left(R-R_{\min }\right) /\left(R_{\max }-R_{\min }\right)$, where $R(\mathrm{~mm})$ is the actual soil water content, $R_{\min }(\mathrm{mm})$ the minimum soil water content measured during the experiments, and $R_{\max }(\mathrm{mm})$ is the soil water content at field capacity.

Midday stem water potential $\left(\Psi_{\text {stem }}\right)$ was measured once every two weeks during the two irrigation seasons. We sampled one leaf per tree from two representative trees per plot. The leaves were wrapped in aluminium foil ca. $2 \mathrm{~h}$ before the measurement with a Scholander-type pressure chamber (PMS Instrument Company, Albany, Oregon, USA).

At the beginning of each irrigation season, we installed two sets of heat-pulse velocity (HPV) probes (Tranzflo NZ Ltd., Palmerston North, New Zealand) into the trunk of a representative tree per plot, in three plots per treatment. Sap flow (SF) measurements were made by the $\mathrm{Tz}$ heat-pulse method (Green et al., 2003). Each set had two temperature probes, located at $5 \mathrm{~mm}$ upstream and $10 \mathrm{~mm}$ downstream of a linear heater probe. Each temperature probe had four thermocouples, at 5, 10, 15 and $20 \mathrm{~mm}$ below the cambium. One set of HPV probes faced east and the other west. Heat pulses $(60 \mathrm{~W}$ over 1 s) were applied once every $30 \mathrm{~min}$. Both the firing of the heat pulses and the recording of the outputs from the probes was made by a CR10X Campbell datalogger (Campbell Scientific Inc, North Logan, USA). The system worked continuously for the whole irrigation seasons. The method was validated for olive by Fernández et al. (2006). We followed their procedure for processing the HPV outputs. After averaging the outputs of the two probe sets per tree, we calculated the daily tree water consumption $\left(E_{\mathrm{p}}, \mathrm{L}\right.$ tree $^{-1}$ day $\left.^{-1}\right)$. For each RDI treatment we calculated the $\mathrm{D}_{E \mathrm{p}}$ index as the daily difference between the RDI trees and the control trees for the $E_{\mathrm{p}}$ (Cuevas et al., 2012).

The daily FAO-56 Penman-Monteith $\mathrm{ET}_{\mathrm{o}}$ values required for calculating $\mathrm{ET}_{\mathrm{c}}$ were collected from a nearby standard weather station belonging to the Agroclimatic Information Network of the Junta of Andalusía.

We used linear mixed models (LMM) to analyze the effects of the irrigation treatment (fixed factor) on REW and $\Psi_{\text {stem. }}$. We used leaf identity within plot as the 
random factor structure in the $\Psi_{\text {stem }}$ analysis to describe appropriately our experimental design and deal with the non-independent nature of the spatial experimental design. In REW analysis the random factor was not necessary as we only have one measurement per plot. When no normal and homoscedastic residuals were obtained, appropriate transformation of the variable was used. The model parameters were determined using the restricted maximum likelihood (REML) approach. These analyses were conducted with the R package 'nlme R'.

\section{RESULTS AND DISCUSSION}

The irrigation supplies amounted to average values over the two experimental years of $478 \mathrm{~mm}$ for FI, $290 \mathrm{~mm}$ for 60RDI and $131 \mathrm{~mm}$ for 30RDI. These amounts were $104 \%, 64 \%$ and $29 \%$, respectively, of IN. REW for FI showed soil water conditions close to field capacity along the two irrigation seasons (Figs. 2c,d). For the RDI treatments REW values showed significant decreases in the available soil water from early July, soon after the IAs were reduced in these two treatments once the period for maximum rate of pit hardening was over (Fig. 1). From late August the 60RDI trees were irrigated daily to replace IN, which caused a quick increase in REW. In the 30RDI trees, however, the increase was negligible in 2011, and small in 2012, in accordance to the reduced IAs applied at that time of the year in that treatment, which amounted to $30 \% \mathrm{IN}$.

The seasonal courses of $\mathrm{ET}_{\mathrm{o}}$ (Fig. 3) were as usual in the area. The highest values were recorded from mid-June to late August, and decreasing $\mathrm{ET}_{\mathrm{o}}$ values were recorded from the beginning of September onwards throughout the autumn. Most rainfall events were recorded from early autumn (Fig. 3).

The seasonal courses of the daily $E_{\mathrm{p}}$ values estimated from our sap flow records collected in the two irrigation seasons are depicted in Fig. 4. For comparison between treatments, the shown $E_{\mathrm{p}}$ values are relative to a value of $7 \mathrm{~L}^{-1} \mathrm{ee}^{-1}$ day $^{-1}$ on day of year (DOY) 164 , a figure close to the actual $E_{\mathrm{p}}$. From all treatments, the greatest $E_{\mathrm{p}}$ values were recorded in the FI trees until early September, in accordance to the high IAs supplied in that treatment. From that date the $E_{\mathrm{p}}$ values in the 60RDI trees became similar, or even greater (2011) than those in the FI trees, which is not surprising because both treatments received similar IAs at that time of the year.

As expected, the seasonal courses of $\Psi_{\text {stem }}$ (Figs. 5a,b) evolved according to the IAs applied in each treatment and to the weather conditions. The $\Psi_{\text {stem values in the FI }}$ trees were always over $-1.4 \mathrm{MPa}$, a threshold for water stress in olive with high crop load (Moriana et al., 2012). From early July to late August, the 60RDI trees showed lower

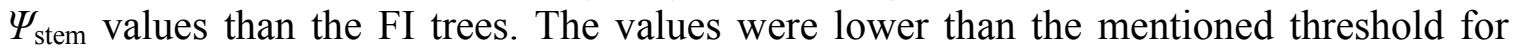
water stress. They recover soon after the increase in IA from late August, to values similar to those recorded in the FI trees. In 2011 the 30RDI trees did not fully recovered from water stress, at least during our monitoring period. In 2012 the 30RDI recovered around DOY 275, thanks to the rainfall events collected on DOY 271 and 272 (Fig. 3b).

In 2011 the time courses of the $D_{E \mathrm{p}}$ values (Fig. 5c) showed similar trends than those of $\Psi_{\text {stem }}$, both for 60RDI and 30RDI. Thus, lower values of $D_{E \mathrm{p}}$ were found for 30RDI than for 60RDI soon after the beginning of the irrigation period, and changes in the slope of $D_{E \mathrm{p}}$ agreed with those of the $\Psi_{\text {stem }}$ curves. This applies even to the period of recovery from water stress after the mid-summer months of high atmospheric demand and low IA. Still, we have some concerns on the marked decrease on $E_{\mathrm{p}}$ shown by the FI trees in 2011, from DOY ca. 250 (Fig. 4a). At that time of the year we were expecting similar $E_{\mathrm{p}}$ values in FI and in 60RDI trees, but we detected unusually high cross-over time $\left(t_{\mathrm{z}}\right)$ 
values from some of the HPV probes installed in the FI trees. The HPV system seemed to be working properly, and we have no explanation for the low sap flux values. We speculated that the sap fluxes in the xylem portions explored by the probes could have been affected by Verticillium dahlia. A small number of trees in the orchard showed symptoms of being infested by the fungus. Our trees showed no visual symptoms, but they do not appear until the damage is severe. Whatever the reason, it is obvious that any factor altering the relationship between $E_{\mathrm{p}}$ and plant water stress will limit the reliability of the $D_{E \mathrm{p}}$ index.

In 2012 the atmospheric demand was quite variable from ca. DOY 200 to DOY 240 (Fig. 3b). This affected the $D_{E \mathrm{p}}$ values derived for that period (Fig. 5d). Cuevas et al. (2012) evaluated $D_{E \mathrm{p}}$ as indicator of water stress in the same orchard, with the same water treatments, and concluded that $D_{E \mathrm{p}}$ was a useful water stress indicator for the orchard conditions. Still, they pointed out two possible sources of error. First, a high tree-to-tree variability for the $D_{E \mathrm{p}}$ records, to the point that three instrumented trees seemed a too low number for getting reliable information. Second, they observed that a significant decrease in the atmospheric demand usually has a stronger influence on the $E_{\mathrm{p}}$ of FI trees than in that of RDI trees. This is because the $E_{\mathrm{p}}$ of the RDI trees is already restricted by the limited soil water. These findings proved that a sudden increase in $D_{E \mathrm{p}}$ does not necessarily mean an improvement of the soil water status. Our 2012 results confirm that in periods of high $\mathrm{ET}_{\mathrm{o}}$ fluctuation the index may not inform properly on the plant water status, as shown (Figs. 5b,d). The index became reliable again from DOY 240, when the daily $\mathrm{ET}_{\mathrm{o}}$ values were less variable. Still, a new peak was registered on DOY ca. 272, in agreement with the marked $\mathrm{ET}_{\mathrm{o}}$ decrease in DOYs 271 and 272.

The variability of the $D_{E \mathrm{p}}$ index due to causes different than changes on the actual water status of the trees could be reduced by increasing the number of instrumented trees, as Cuevas et al. (2012) suggested. We decided, however, to run our evaluation exercise with three instrumented trees per treatment, because of economic reasons. As pointed out by other authors (Naor 2006), a suitable indicator for scheduling irrigation must be inexpensive and easy to operate and maintain. Rather than increasing the number of instrumented trees, which will go against those characteristics, we believe that the factor to be improved is the representativeness of the instrumented trees. This can be achieved with the help of soil maps and airborne thermal images of the orchard (Zarco-Tejada et al., 2009).

\section{CONCLUSIONS}

Our results confirm the limitations of the $D_{E \mathrm{p}}$ index for monitoring tree water stress in SHD olive orchards previously reported by Cuevas et al (2012). Thus, three replicas per treatment seems to be too little for obtaining reliable $D_{E \mathrm{p}}$ values and sudden decreases in $\mathrm{ET}_{\mathrm{o}}$ reduced $E_{\mathrm{p}}$ proportionally more in FI trees than in RDI trees, which causes a loss of reliability of the $D_{E \mathrm{p}}$ index on periods of high atmospheric demand fluctuations. We suggest the use of soil maps and remote imagery for choosing more representative trees, rather than increasing the number of instrumented trees. Despite the limited performance of the index with fluctuating $\mathrm{ET}_{\mathrm{o}}$, the time course of the index was similar to that of $\Psi_{\text {stem }}$ on periods of low $\mathrm{ET}_{\mathrm{o}}$ variability, which are common during the olive irrigation season. In addition, the $D_{E \mathrm{p}}$ index showed to be robust and suitable for continuous and automatic monitoring of the trees' water stress under commercial orchard conditions. We conclude, therefore, that the $D_{E \mathrm{p}}$ index is useful for monitoring water stress in SHD olive orchards, and it has a potential for scheduling RDI strategies. Still, 
both the analysis of the sap flow data for deriving the index and the noise caused by changing weather conditions requires the index to be applied by well-trained people.

\section{ACKNOWLEDGEMENTS}

This work was funded by the Spanish Ministry of Science and innovation (research project AGL2009-11310/AGR), by the Junta de Andalucía (research project AGR-6456-2010) and by the FEDER programme. Antonio Montero helped us with the field and laboratory work. We thank the owners of Internacional Olivarera, S.A.U. (Interoliva), Silvia Seller, agronomist, and Juan Francisco Bernabé, foreman.

\section{Literature Cited}

Connor, D.J. 2006. Towards optimal designs for hedgerow olive orchards. Aus. J. Agric. Res. 57:1067-1072.

Cuevas, M.V., Martín-Palomo, M.J., Díaz-Espejo, A., Torres-Ruiz, J.M., RodriguezDominguez, C.M., Perez-Martin, A., Pino-Mejías, R. and Fernández, J.E. 2012. Assessing water stress in a hedgerow olive orchard from sap flow and trunk diameter measurements. Irrig. Sci. DOI 10.1007/s00271-012-0357-X.

Fernández, J.E., Durán, P.J., Palomo, M.J., Diaz-Espejo, A., Chamorro, V. and Girón, I.F. 2006. Calibration of sap flow measurements by the compensation heat-pulse method in olive, plum and orange trees: relations with xylem anatomy. Tree Physiol. 26: 719-728.

Fernández, J.E., Rodriguez-Dominguez, C.M., Perez-Martin, A., Zimmermann, U., Rüger, S., Martin-Palomo, M.J., Torres-Ruiz, J.M., Cuevas, M.V., Sann, C., Ehrenberger, W. and Diaz-Espejo, A. 2011. Online-monitoring of tree water stress in a hedgerow olive orchard using the leaf patch clamp pressure probe. Agric. Water Manage. 100:25-35.

Gómez-del-Campo, M. 2011. Summer deficit-irrigation strategies in a hedgerow olive orchard cv. 'Arbequina': effect on fruit characteristics and yield. Irrig. Sci. DOI 10.1007/s00271-0299-8.

Grattan, S.R., Berenguer, M.J., Connell, J.H., Polito, V.S. and Vossen P.M. 2006. Olive oil production as influenced by different quantities of applied water. Agric. Water Manage. 85:133-140.

Green,S.R., Clothier, B.E. and Jardine,B. 2003. Theory and practical application of heatpulse to measure sap flow. Agron. J. 95:1371-1379.

León, L., de la Rosa, R., Rallo, L., Guerrero, N. and Barranco, D. 2007. Influence of spacing on the initial production of hedgerow 'Arbequina' olive orchards. Span. J. Agric. Res. 5:554-558.

Moriana, A., Pérez-López, D., Prieto, M.H., Ramírez-Santa-Pau, M. and PérezRodriguez, J.M. 2012. Midday stem water potential as a useful tool for estimating irrigation requirements in olive trees. Agric. Water Manage. 112:43-54.

Naor, A. 2006. Irrigation scheduling and evaluation of tree water status in deciduous orchards. Hortic. Rev. 32:111-165.

Zarco-Tejada, P.J., Berni, J.A.J., Suárez, L., Sepulcre-Cantó, G., Morales, F. and Miller, J.R. 2009. Imaging chlorophyll fluorescence with an airborne narrow-band multispectral camera for vegetation stress detection. Remote Sensing Environ. 113:12621275 . 


\section{Figures}

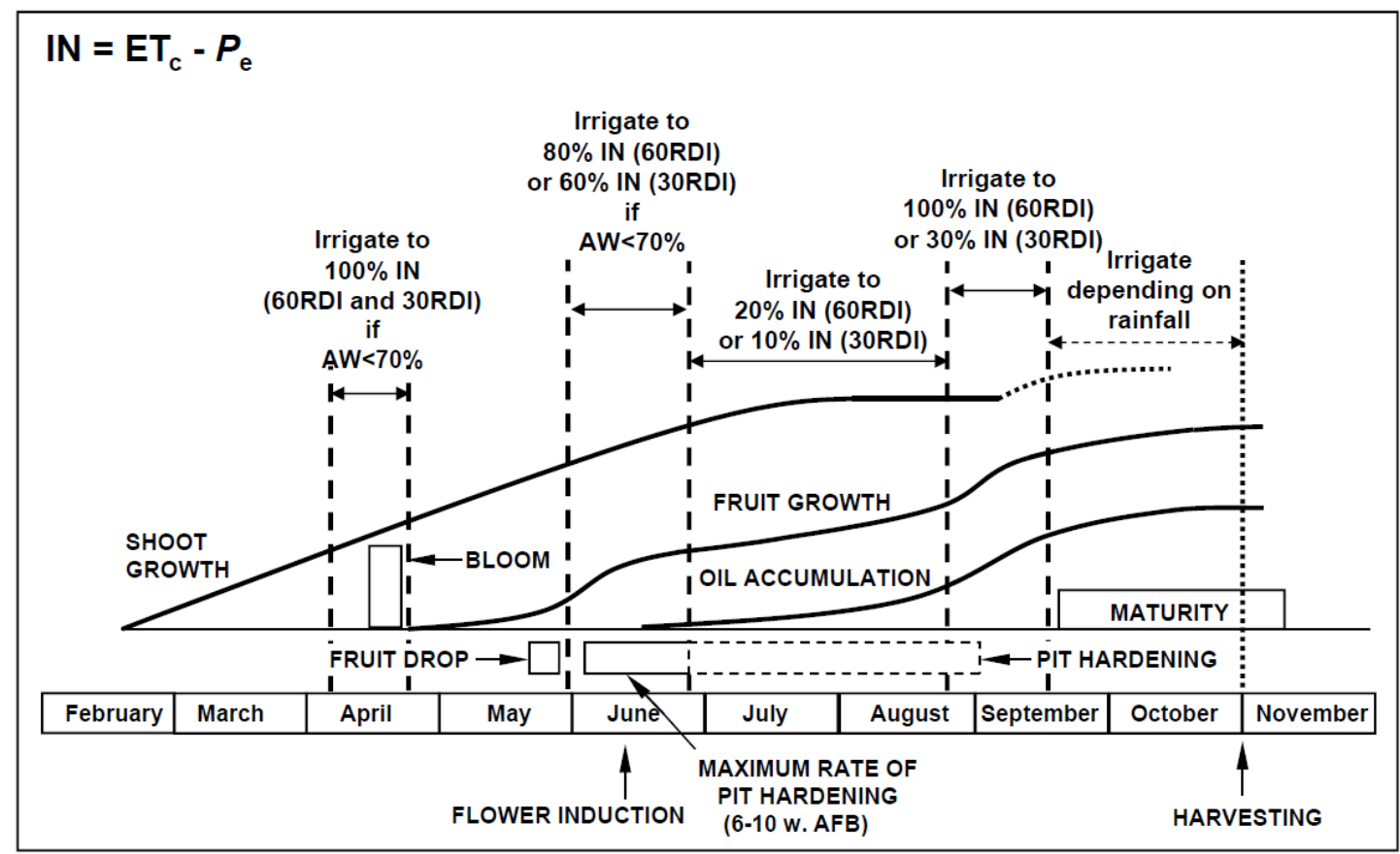

Fig. 1. Regulated deficit irrigation strategies applied in the experimental orchard (60RDI and 30RDI). For 60RDI, daily irrigation supplies were applied in the indicated periods of April and June, as well as from late August to mid-September. In July and August the 60RDI trees were irrigated twice per week. For 30RDI, daily irrigation supplies were applied in the indicated periods of April and June only. From late August to mid-September the 30RDI trees were irrigated twice per week. In July and August the 30RDI trees were irrigated once per week only. Dates for the different phenological stages may change depending on the year, location, cultivar and management practices, among other factors. The dates shown in the figure correspond to our experimental periods. The depicted curves of shoot growth, fruit growth and oil accumulation are typical curves for olive trees growing under non limiting soil water conditions. The shape of these curves may also change under different soil and atmospheric water conditions, among other factors. $\mathrm{IN}=$ irrigation needs; $\mathrm{ET}_{\mathrm{c}}=$ crop evapotranspiration; $P_{\mathrm{e}}=$ effective precipitation; $\mathrm{AW}=$ available water in the soil; $\mathrm{w}$. $\mathrm{AFB}=$ weeks after full bloom. 


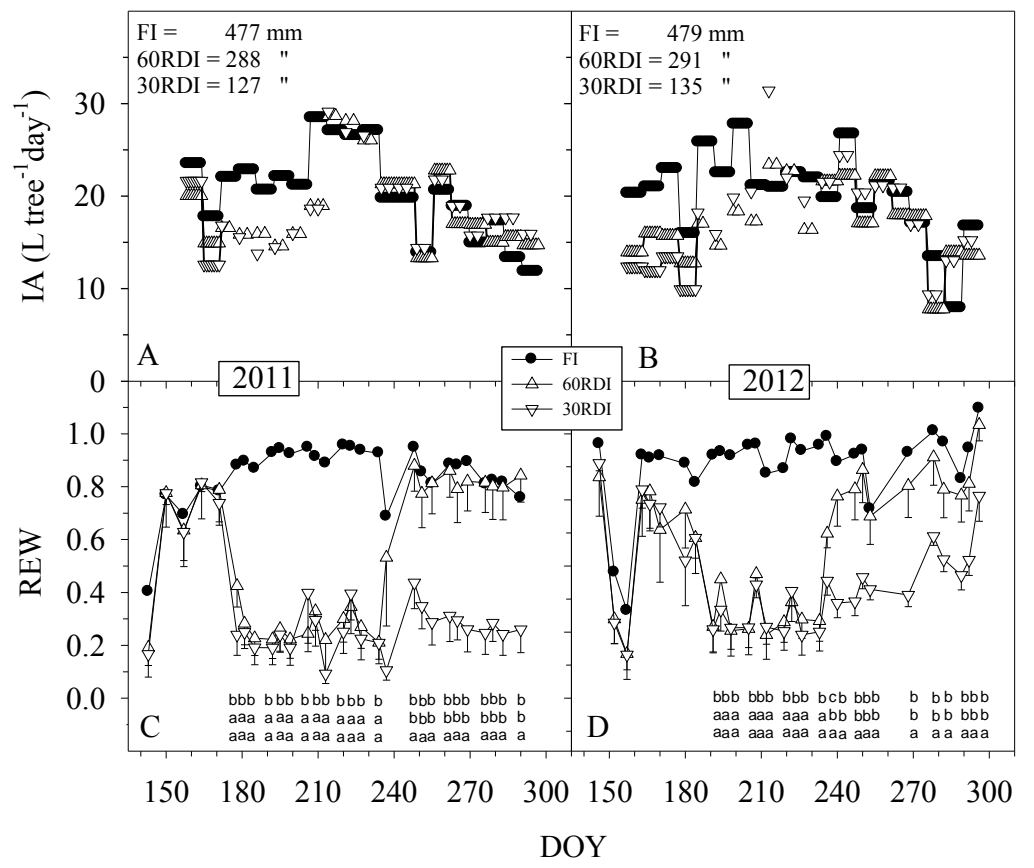

Fig. 2. Sea:

the

trea

rela

the

and

betv

found. 1

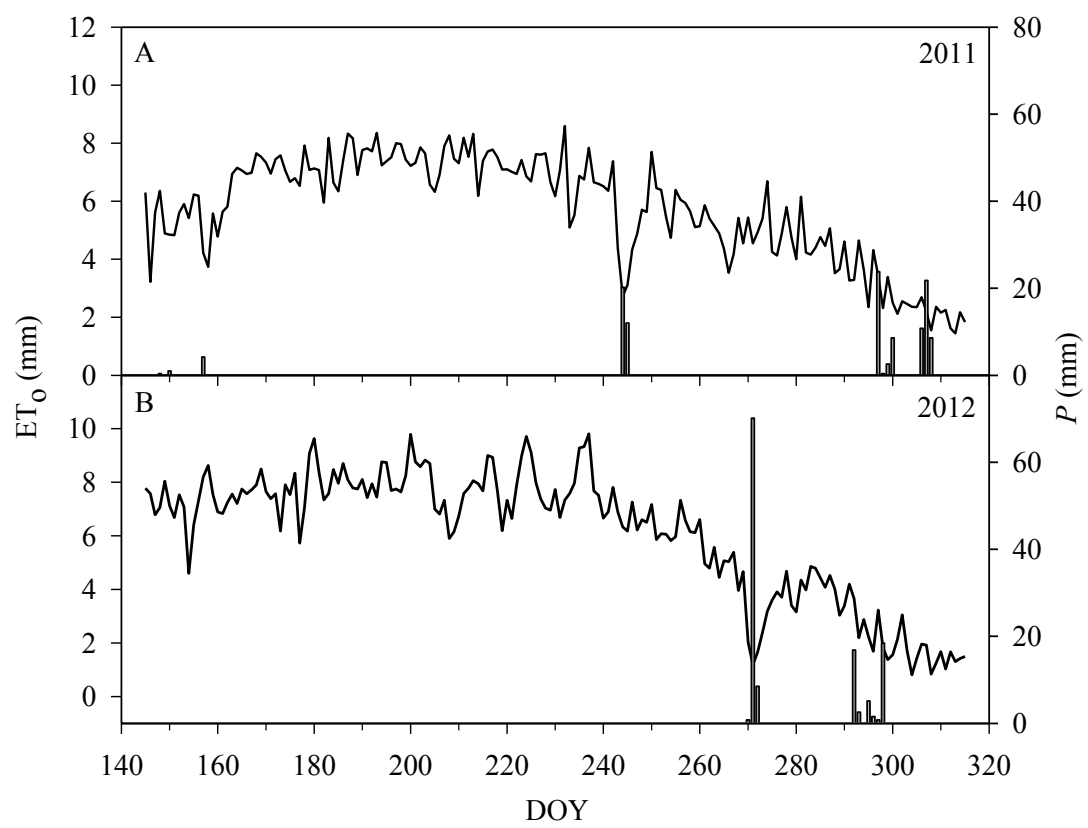

Fig. 3. Seasonal courses of the potential evapotranspiration $\left(\mathrm{ET}_{\mathrm{o}}\right)$ and precipitation $(P)$ values in the orchard. DOY = day of year 


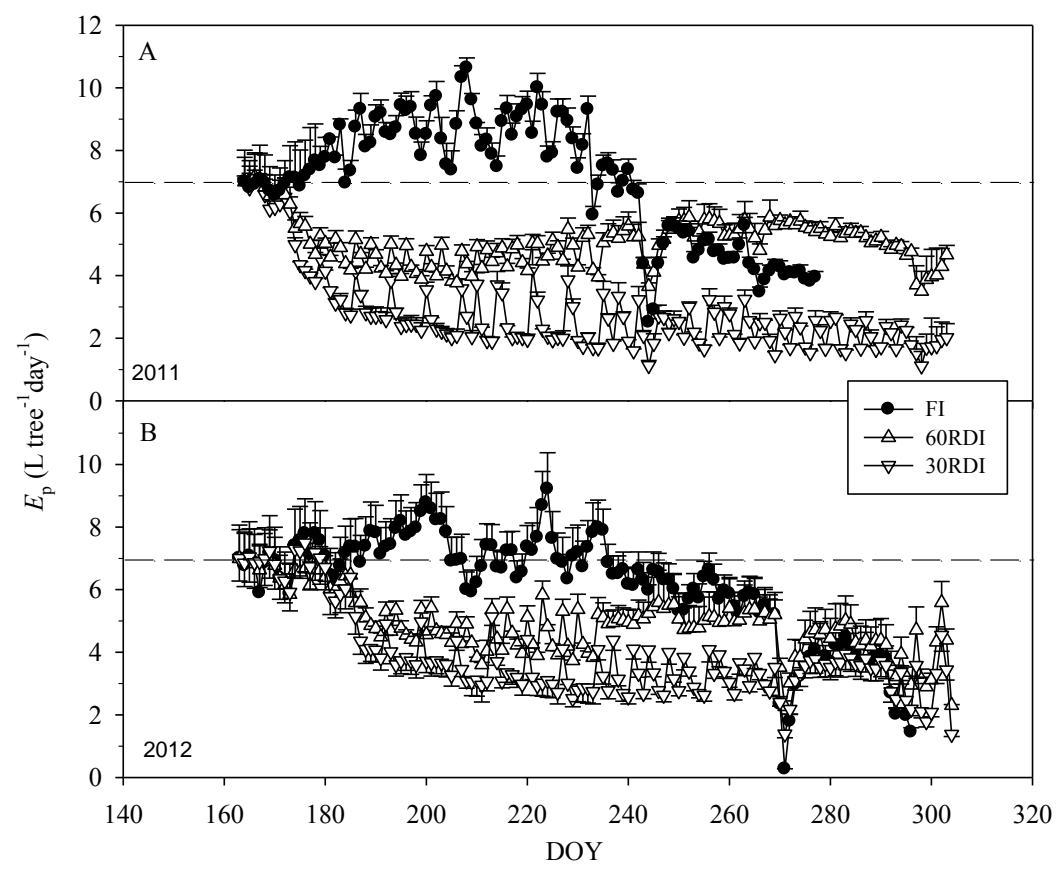

Fig. 4. Seasonal courses, for the two experimental seasons, of the daily tree water consumption $\left(E_{\mathrm{p}}\right)$ estimated from sap flow records. Data are the average of three trees per treatment. Vertical bars are the standard error. DOY = day of year.

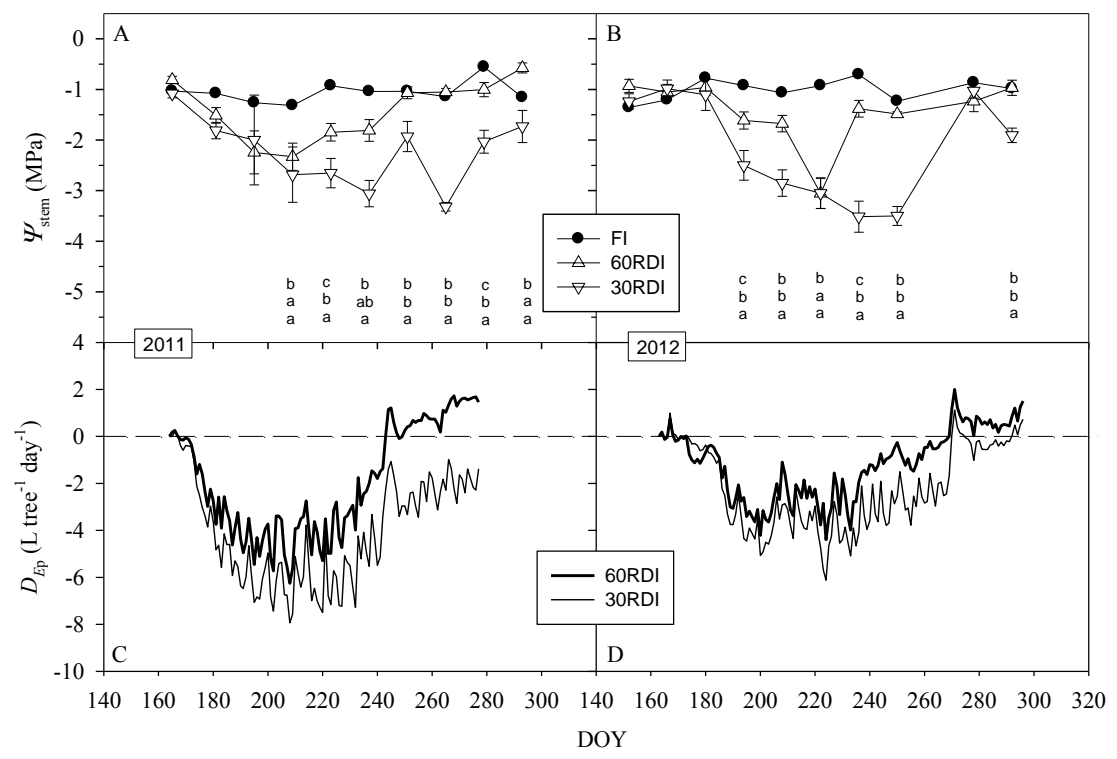

Fig. 5. Seasonal courses of the midday stem water potential $\left(\Psi_{\text {stem }}\right)$ values measured in representative trees of each treatment (graphs A and B). Each point represents the average \pm the standard error $(n=8)$. Different letters indicate significant differences between treatments at $p<0.05$. Letters are not shown when no differences were found. Also shown are the daily differences between the average tree transpiration $\left(E_{\mathrm{p}}\right)$ in each RDI treatment minus the average $E_{\mathrm{p}}$ values in the FI treatment $\left(\mathrm{D}_{E \mathrm{p}}\right)$ (graphs $\mathrm{B}$ and $\mathrm{C}$ ). The $E_{\mathrm{p}}$ values used for calculating $\mathrm{D}_{E \mathrm{p}}$ were derived from sap flow records in three trees per treatment. DOY $=$ day of year. 